\title{
Health literacy: Where are the Canadian doctors?
}

\author{
Irving Rootman
}

A $\mathrm{s}$ a Canadian member of the US Institute of Medicine (IOM) Committee on Health Literacy, ${ }^{1}$ I was impressed with the extent to which individual physicians and medical institutes have led the way in putting the issue of health literacy* on professional and political agendas in the United States. Not only did individual physicians undertake considerable research on health literacy, but the American Medical Association (AMA) established an Ad Hoc Committee on Health Literacy, which produced an influential report $^{2}$ that contributed to the identification of health literacy as a health goal for the United States and to the establishment of the IOM Committee on Health Literacy and the support of health literacy initiatives through the AMA Foundation.

\section{The Canadian medical com-}

\section{munity has not been very active in health literacy.}

In striking contrast, the documented contribution of individual physicians and organized medicine in Canada to the field of health literacy has been limited. Little research has been conducted on health literacy by Canadian physicians, and leadership in this field has been located instead among the nonphysician members of the provincial and national public-health associations. ${ }^{3}$ This is not to say that Canadian physicians and their organizations have been totally inactive - the Canadian Medical Association has been a member of the National Literacy and Health Program, and a handful of Canadian physicians have spoken out about the importance of literacy and health and done some research - but certainly not to the same degree as medical organizations and physicians in the United States.

Why this striking difference between Canada and the United States should exist is unclear. Linda Shohet, the Director of the Centre for Literacy of Quebec, has speculated (personal communication, 2006 June I6) that:

* There are many definitions of health literacy. The one adopted by the IOM Commitee on Health Literacy was "The degree to which individuals have the capacity to obtain, process and understand basic health information and services needed to make appropriate health decisions" (p. 4). 'However, the committee also stressed the point that health litracy was a result of an interaction between the individual and the different health contexts in which they seek or receive health information.
In the US, the initiators of research into health literacy were physicians, which may have been purely by chance. Once they opened up the question, it seems to have established the topic as one worthy of a physician's attention. From there, the large associations like the AMA picked it up, giving it further credibility.

I have wondered if the American preoccupation with liability has played some part. There is a case law of suits brought against physicians for not ensuring that patients understood a course of treatment, etc., and literacy levels have been mentioned.

The organization of health care may also be involved. Because there are such gaps in access (in insurance, quality, etc.) between the poor and the rich or middle class that there may be more [US] awareness of issues of equity and access, and literacy becomes one of the markers for potential exclusion.

In Canada, the first interest in health literacy came from nurses, which may have "marked" it as beneath a physician's attention; there is still a considerable hierarchy inside the medical field. Those physicians most likely to focus on the issue are family doctors, but we don't have enough of them. We may also be less sensitive to questions of access because [our habituation to] Medicare suggests that everyone has it. When we do address the question, it's often through the lens of cultural sensitivity, without ever linking it to literacy and language.

These may or may not be valid explanations. Whatever the reasons, it is unfortunate that the Canadian medical community has not played a more active role in health literacy, since it is clearly an important issue in the practice of medicine. Moreover, it is an issue that can be addressed constructively by physicians and their professional organizations.

There are key reasons why Canadian physicians should be more concerned about health literacy. First, the most recent International Adult Literacy and Skills Survey (IALSS, released in 2005) found that almost half of the Canadian adult population fell into the lowest 2 of 5 levels (defined on p. I6-I7 of reference 4) in terms of their ability to read and understand prose (48\%) and documents (49\%), and more than half fell into those 2 lowest levels in numeracy (55\%) and problemsolving skills $(72 \%){ }^{4}$

Second, the IALSS showed that rates of low literacy were significantly higher among older adults, francophones, aboriginal people, immigrants and residents of certain provinces or territories. ${ }^{4}$

Third, studies have found that lower literacy or health literacy was associated with poorer self-reported health, inappropriate medication use and noncompliance with physician orders, poorer glycemic control and increased prevalence of self-reported complications that resulted from poor control, less health knowledge, less sharing in decision-making about 
treatment, less expression of health concerns and worse communication with practitioners. ${ }^{3}$

Fourth, much of the material used in physician practices in Canada for patient education may be written at a higher level than it ought to be. A recent study in a Montreal clinic, ${ }^{5}$ for example, found that the average reading level of patient education materials in the practice was grade II.5, higher than the recommended reading level of grade 7 or less.

Clearly, Canadian physicians and medical organizations have as much reason to be concerned about health literacy as their American counterparts. Fortunately, there are things that both individual physicians and their organizations can do to address these issues.

Individual physicians could, for example, become more aware of the magnitude of the issue of low literacy and health literacy in the population and in their own practices. They also might become more sensitive to the signs of low literacy and health literacy among their patients and adjust their oral and written communication accordingly. In particular, they could screen their patient education materials to ensure that they are at an appropriate level for a general practice ${ }^{6}$ and also adopt communication approaches that have been found to be effective with people with low levels of health literacy, such as the "teach-back" approach, which involves asking the patient to restate what he or she understood from what the doctor has said. ${ }^{7}$ Some might also undertake or collaborate in research to determine the levels and distribution of health literacy among their patients and to evaluate the effectiveness of interventions.

As for physician organizations, they might either initiate new efforts or renew previous ones to advocate for policies and programs related to health literacy. They might also support current promising initiatives to address health literacy in Canada. Two such initiatives are sponsored by the Health and Learning Knowledge Centre of the Canadian Council on Learning: the Expert Committee on Health Literacy, organ- ized by the Canadian Public Health Association, and a project to strengthen the education of health professionals in patient self-management and health literacy organized by the $\mathrm{BC}$ Academic Health Council.

Whatever is decided by individual physicians or their organizations, their more active involvement in the field of health literacy would be welcome and timely, especially given the fact that the issue of health literacy is gaining momentum in the United States and Europe.

This article has been peer reviewed.

Irving Rootman, $\mathrm{PhD}$, is a professor and Michael Smith Foundation for Health Research Distinguished Scholar at the University of Victoria, Victoria, BC.

Competing interests: None declared.

Acknowledgements: I am grateful to Marg Rose and Linda Shohet for their suggestions and comments.

\section{REFERENCES}

I. Institute of Medicine of the National Academies. Health literacy: a prescription to end confusion. Washington: National Academies Press, 2004.

2. American Medical Association, Ad Hoc Committee on Health Literacy. Health literacy: report of the Council on Scientific Affairs. JAMA I999;28I:552-7.

3. Rootman I, Ronson B. Literacy and health research in Canada: Where have we been and where should we go? Can J Public Health 2005;96(Suppl 2):S62-77.

4. Statistics Canada. Building our competencies: Canadian results of the international adult literacy and skills survey. Ottawa: Statistics Canada; 2005.

5. Smith JL, Haggerty J. Literacy in primary care populations: Is it a problem? Can J Public Health 2003;94:408-I2.

6. Bennett IM, Robbins S, Haecker T. Screening for low literacy among adult caregivers of pediatric patients. Fam Med 2003;35:585-90.

7. Schillinger D, Bindman A., Wang F, et al. Functional health literacy and the quality of physician-patient communication among diabetes patients. Patient Educ Couns 2004;52:315-23

Correspondence to: Dr. Irving Rootman, Centre for Community Health Promotion Research, University of Victoria, University House \#3, Box 306o, Stn. CSC, Victoria BC V8W $3 \mathrm{R}_{4}$; irootman@uvic.ca

\section{Holiday Review 2006 Call for submissions}

Hilarity and good humour ... help enormously in both the study and the practice of medicine ... [I]t is an unpardonable sin to go about among patients with a long face. - William Osler

Yes, that's right, it's time to send us your creative contributions for CMAf's Holiday Review 2006. We're looking for humour, spoofs, personal reflections, history of medicine, off-beat scientific explorations and postcards from the edge of medicine.

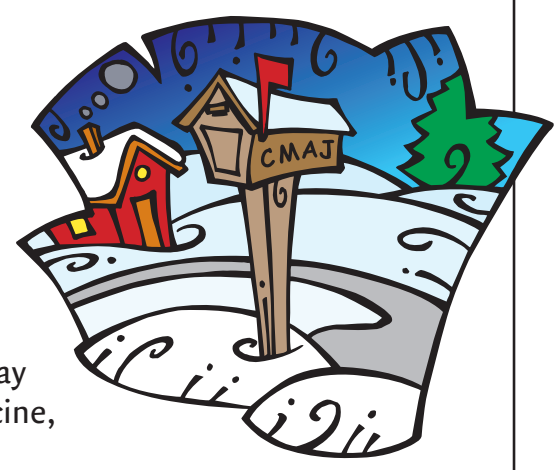

Send your offerings through our online manuscript tracking system (http://mc.manuscriptcentral.com/cmaj). Articles should be no more than 1200 words; photographs and illustrations are welcome. Please mention in your cover letter that your submission is intended for this year's Holiday Review.

The deadline for submissions is Oct. 16, 2006. 